\title{
Familial adrenal hypoplasia with absent pituitary luteinizing hormone
}

INSERM

\section{Source}

INSERM. (1999). Orphanet: an online rare disease and orphan drug data base. Familial adrenal hypoplasia with absent pituitary luteinizing hormone. ORPHA:95700

Familial adrenal hypoplasia with absent pituitary luteinizing hormone is a rare endocrine disease characterized by a miniature adult type of congenital adrenal hypoplasia (residual adrenal cortex is composed of a small amount of permanent adult cortex with normal structural organization), selective absence of pituitary luteinizing hormone in otherwise normal brain, and neonatal demise. Patients present with hypogonadotropic hypogonadism, hypoglycemia, seizures, encephalopathy and diabetes insipidus. There have been no further descriptions in the literature since 1988. 